\title{
An Assessment of School Going Population Exposure Pathways to Agropesticide in the Mungo Corridor of Cameroon
}

\author{
Efuetlancha Ernest Nkemleke, PhD Student, \\ Martin Kuete, Professor \\ Department of Geography, University of Dschang, Cameroon
}

Doi:10.19044/esj.2020.v16n26p123 URL:http://dx.doi.org/10.19044/esj.2020.v16n26p123

\begin{abstract}
Pesticide use in agricultural holdings closer to dwellings exposes the population to its noxious effects. This study is set on the premise that although pesticide seems a panacea for crop protection, it has continued to wreak havoc on farmers' health and especially school going population who are exposed to pesticide use in nearby agroindustrial plantations in the Mungo Corridor. The study objectives are to identify students who use pesticides and why they use these toxic chemicals. In this same vein, it probes into identifying some common pesticides exposure pathways among students and the resultant effects of these toxic chemicals on them. The study employed both primary and secondary data, and key informant interviews with resource persons. Data was collected through a survey of 510 students across 10 schools in two subdivisions. Data analysis was run on Microsoft Excel 2016 and SPSS 16.0, employing descriptive (percentage indices, charts, mean, median) and inferential (Kruskal-Wallis (H-Test), Mann Whitney (U-Test), and ChiSquare test) statistics. Findings revealed that school going population is potentially exposed to pesticides via different exposure pathways, justified by the proximity of schools to agroindustrial banana plantations where pesticides are sprayed using helicopters. Also, majority of students (85\%) use pesticides for various reasons with little or no knowledge on the methods of use which further broadens their exposure. A weighted analysis of data revealed that there was a significant difference between students' education level and some hypothesized explanatory variables $(\mathrm{p}<0.05)$, implying that lack of information by students on how to avoid contacts with pesticides further exposes them. However, the paper concludes that receiving training in the safe use of pesticides by students and providing wind barriers in agroindustrial banana plantations to prevent spray drifts from entering into school yards and residence are key solutions to this danger.
\end{abstract}


Keywords: Agropesticide, agroindustrial plantations, school going population, exposure pathways, health symptoms, Mungo Corridor, Cameroon

\section{Introduction}

Pesticides are frequently used on crops against pests and diseases but their negative effects have been a public health issue for many years. This is why Morgan (2012) posits that there has been a growing public health concern about children's exposure and potential health risk to pesticide. These pesticides affect school going population because of the proximity of school environment to agricultural lands. This environment is one which provides opportunity for both the regular (normal) and special needs (challenged) students to learn together in the same school and classroom environments (Ekeh \& Njoku, 2014). Some of these learners may include the hearing impaired, visually impaired, learning disabled, physically and health impaired, the gifted and talented and mild mentally retarded which can be attributed to long term exposure to pesticides.

Children and/or school going population are vulnerable to pesticide due to their increased consumption of air, food, and water (Hurley et al., 2014). They are more exposed to environmental toxins than adults, due to the fact that their activities influence both exposure and dose. This hypothesis has been widely supported. Nicholas et al. (2005) report that between 2001 and 2003, more than twenty eight per cent of children in one urban center were affected. However, much has been documented on pesticides effects on the health of farmers, workers in agroplantations and agrochemical dealers because they handle, manipulate and use these toxic chemicals on a daily basis. A neutral population - school going population, is potentially vulnerable to these chemicals through various exposure pathways and little or no research has been done to report such findings.

Also, Hurley et al., (2014) show that pesticides are valuable tools to help reduce risks associated with pests. However, studies suggest their use generally, and especially in schools, childcare settings, and other sensitive environments should be carefully managed and minimized especially the school climate. This is why Okorji et al., (2016) show that school climate represents all the constituent aspects of the school: the physical; social; academic and affective aspects of the school. When this physical environment is exposed to toxins, the entire school population is no exception.

The Mungo Corridor is a vast agricultural production basin in the Littoral Region of Cameroon dominated mainly by cash crop production such as banana, oil palm, cocoa, and coffee among others, with some food crops, vegetables and fruits widespread. Owing to these numerous agricultural 
activities carried out within this corridor, chemical pesticides have been intensified in crop production both for household consumption and for the market (mainly for export). Apart from the numerous advantages of these pesticides on crops production, the disadvantages are enormous and in multiple facets: Toxic to plants if over-dosed; toxic to aquatic ecosystem; farmers and the entire population living nearer to sprayed fields.

However, the regulatory process for pesticides is not a guarantee of safety. Although, the state of Cameroon's pesticides regulatory agencies have taken actions to ensure proper use of these chemicals and even prohibit or restrict the use of some pesticides in agriculture, the respect of these actions has not been satisfactory as pesticides users defy the rules and regulations on the safe use of these chemicals. This is therefore where a great chain of contamination and environmental pollution takes root.

The negative effects of pesticides are not only seen on ordinary farmers who handle and spray these chemicals on a daily basis, these effects are also recurrent on school going population who are either exposed to these toxic chemicals use in agroindustrial plantations where aerial sprays by helicopters are done closer to schools or they are exposed via personal contacts with pesticides during on-farm activities. It is therefore within this framework that the thrust of this paper is to identify students who use pesticides, assess the reasons for the use of pesticides by school going population, identify some common factors influencing school going population exposure to agropesticides and outline common symptoms/illnesses of pesticides noxious effects amongst school going population.

\section{Materials and Methods}

\subsection{Study Area}

The study was carried out in the Mungo Corridor of the Littoral Region

of Cameroon specifically in Loum and Njombe-Penja (Figure 1). Geographically, it is located between latitudes $4^{\circ} 30^{\prime}$ and $4^{\circ} 43^{\prime}$ North of the Equator, and longitudes $9^{\circ} 35^{\prime}$ and $9^{\circ} 54^{\prime} \mathrm{E}$ of the Greenwich meridian. 
Figure 1: Location of Loum and Njombe-Penja

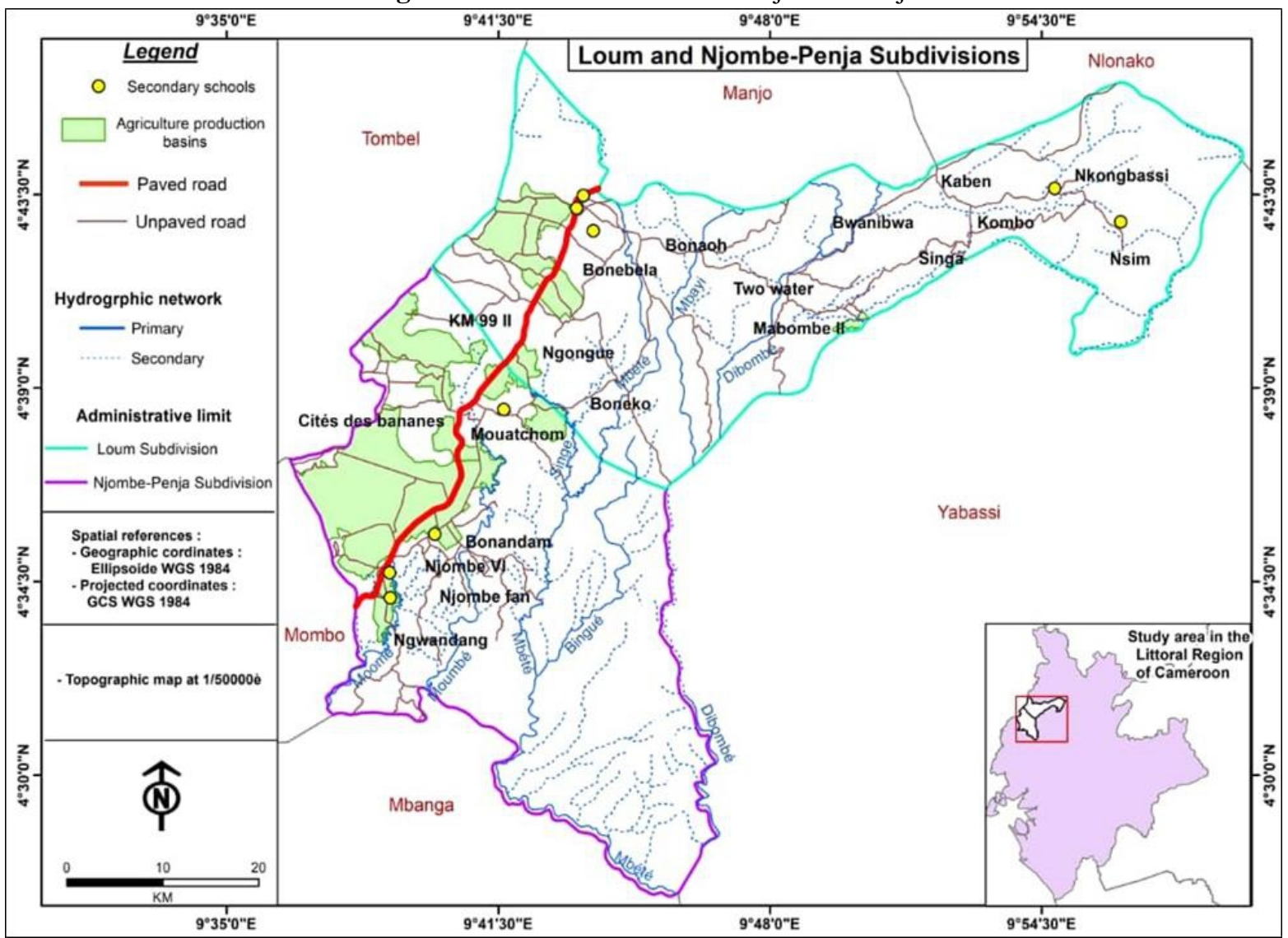

Source: Geo database of NIC 2018, field work. Realised by: Nkemleke

The Mungo Corridor is entirely in the equatorial climatic domain. Rainfall is high (more than $2000 \mathrm{~mm}$ ) but presents significant local variations. In the south of the Mungo, the rainfall decreases towards Mbanga (2300mm), and augments near the mountain ranges $(2700 \mathrm{~mm}$ in Njombe, $3000 \mathrm{~mm}$ in Penja, 2700mm in Nkongsamba), and decreases again at the Northern flanks and North East of the Manenguba, which is less exposed to the humid winds from the South West. This rainfall distribution has a particular allure for an equatorial climate due to the influence of the monsoon during the three months from July to September: a single maximum in September for a 10months of rainfall. The rainy season is established gradually from March, and after a peak in June, very heavy rains are observed from July to October. The dry season lasts particularly only three months (October to January) and it is more marked in the north than the south of the Mungo. The temperature is obviously very variable with altitude: Nkongsamba (870masl-metres above sea level) has an 
average temperature of $24^{\circ} \mathrm{C}$ while Yabassi (40masl), which is closer to Mbanga (120masl), is much warmer $\left(22^{\circ} \mathrm{C}\right)$.

The major settlements in the study area include Loum, Penja, and Njombe. The study area is characterized by a very dense population that are scattered in various settlements. Njombe and Penja are populated by about 50,800 inhabitants with a surface area of about $260 \mathrm{~km}^{2}\left(195\right.$ inhabitants $\left./ \mathrm{km}^{2}\right)$ (Ako et al., 2010). The populations of these towns have witnessed rapid increase between 1987 and 2006. For instance, the population of Njombe and Penja increased from 33,000 to 50,000 while that of Loum went from 67,000 to 110,000 inhabitants (GTZ, 2006). Current projections show that the population of these two subdivisions stands at approximately 320,000 inhabitants ${ }^{5}$ in 2020 . About $40 \%$ of the population of the study area is resident in camps that are located within some of the agroindustrial plantations that characterise the study area.

\subsection{Sampling Procedure}

A multiple phase or multi-stage sampling procedure was employed in laying out this study as used in other related study (Nkemleke, 2020).

Firstly, the Mungo Corridor was purposively selected owing to the high proportion of school going population engaged in pesticides use and their exposure to the negative effects of these chemicals (due principally to their limited knowledge, training in pesticides use and proximity of schools to agroindustrial banana plantations).

At phase two, the study area was grouped into two strata based on their macro and micro agro-ecological characteristics (type of agriculture and crops grown).

At phase three, Stratified Random Sampling (SRS) procedure was conducted wherein; schools were stratified based on their proximity to agroindustrial plantations. Students in these schools were later randomly selected for the survey. This was done with the help of heads of each learning institution in the study area. Older, younger students and students who use pesticides were sampled in order to get more reliable information pertaining to exposure pathways.

Stage four involved Key Informant Interviews (KIIs) with heads of institutions and health personnel. This was conducted in order to ascertain the veracity of the responses given by students during surveys. Administering of structured and semi-structured questionnaires was done through questionnaire ration. A total of 510 students were targeted across ten (10) government and private secondary schools during the survey with a $100 \%$ respondents' rate

${ }^{5}$ According to the formula of population projection $P=P_{o} \times e^{r t}$

Where $\mathrm{P}=$ Population at a future time, $\mathrm{P}_{0}=$ Population at an initial year, $\mathrm{e}=$ the base of the natural logarithm (2.71828), $r=$ rate of increase, $t=$ time period involved. 
(Table 1). The surveys provided information on students' exposure pathways to agropesticides and the causes of school going population vulnerability to these toxic chemicals.

Table 1: Selected schools with sampled students in the Mungo Corridor

\begin{tabular}{clcc}
\hline SN & \multicolumn{1}{c}{ School } & Subdivision & Number of students sampled \\
\hline 1 & GBHS Manengwassa & Loum & 51 \\
2 & CAMEL & Loum & 51 \\
3 & Lycée Technique de Loum & Loum & 46 \\
4 & SAR/SM Badjokip & Loum & 39 \\
5 & GSS Babong & Loum & 28 \\
6 & TISSERINS & Njombe-Penja & 52 \\
7 & GBHS Penja & Njombe-Penja & 21 \\
8 & CETIC de Njombe & Njombe-Penja & 58 \\
9 & GBHS Njombe & Njombe-Penja & 123 \\
10 & Collège Polyvalent Penja & Njombe-Penja & 41 \\
Total & $\quad \mathbf{1 0}$ & $\mathbf{2}$ & $\mathbf{5 1 0}$ \\
\hline
\end{tabular}

Source: Field data, 2019

\subsection{Data Collection Procedure}

Both primary and secondary data were collected for the study: Primary data was collected via a survey of 510 students in ten (10) selected schools (Table 1). While secondary data was gotten from health establishments. Primary data was collected through the administering of semi-structured questionnaires to students in the selected schools. The questionnaire was designed in such a way as to obtain information pertaining to students' sociodemographic parameters, and their practices vis-à-vis pesticides. The survey was beefed up with interviews held with health personnel, heads of the different learning institutions, students and other resource persons; and direct field observations in the study area.

In order to ascertain the veracity of students' responses on the incidence of pesticides contaminations, data on some pesticides related symptoms and illnesses among school going population was gotten from district hospitals and health centres (Table 8).

\subsection{Data Analysis Procedure}

This study made use of some independent explanatory variables (Table 2). Statistical analysis of data was done on the Statistical Package for Social Sciences (SPSS) 16.0 and Microsoft Excel 2016. Both descriptive and inferential statistics were used in the study. Descriptive statistics used were percentage indices, mean, median, interquartile range and chart while inferential statistics used were Kruskal-Wallis (H-Test), Mann Whitney (UTest), and Chi-Square test.

Considering the buffer zone (maximum distance considered to be closer to school and residence with regards to the climatic conditions of the 
area) between schools and agroindustrial plantations, Hurley et al., (2014) show that this zone ranges between 300 feet $(91.44 \mathrm{~m})$ up to $2 \frac{1}{2}$ miles $(4.026 \mathrm{~km})$ for ground and aerial spray of pesticides and any aerial application within this zone is considered risky to the population. To support this hypothesis, other studies (Frost \& Ware, 1970; Chester \& Ward 1984) have also shown that drift from aerial pesticide applications can extend from 500 to $1000 \mathrm{~m}$. In order to determine the proximity of schools to agroplantations considering the climatic conditions of the study area, the geographical distance between schools and agroindustrial plantations was calculated (Table 6).

The H-test was run to test whether there was a significant variation in students' reasons for using pesticides across sampled schools. In order to show if students' ages determine their abilities and zeal to frequently use pesticide, the Mean, Median and Interquartile Range were used. This was done to show the age group that manipulates or uses more pesticides in a whole cropping season. To do this, the following steps were taken:

- Total number of times a student uses pesticides in a whole season was recorded;

- Students $<20$ years of age were considered younger in pesticides use;

- Students $>20$ years of age were considered older in pesticides use;

- Students who have used pesticides for $<5$ years and $>5$ years were also identified.

The U-Test on its part was run to show whether older students who have used pesticides for a period of less than five years frequently use these chemicals on average more than their younger counterparts who have also used pesticides for the same length of time. To do this the following hypotheses were formulated:

$\mathbf{H}_{0}$ : There is no difference between the frequency of pesticides used on average by younger and older students who have all used pesticides for less than five years;

$\mathbf{H}_{1}$ : Younger students tend to use pesticides on average less frequently than older students who have all used these chemicals for less than five years.

The Chi-Square $\left(X^{2}\right)$ test was done to determine if there was a significant difference between students' level of education and some hypothesized explanatory variables. This Chi-Square has also been used in a similar study to decipher small-scale farmers' vulnerability to agropesticides (Nkemleke, 2020). 
Table 2: Description of variables used in the study

\begin{tabular}{|c|c|}
\hline Variable & Description \\
\hline Class & Continuous* \\
\hline Age & Continuous \\
\hline Duration of pesticides use & uous \\
\hline Type: & Continuous \\
\hline Pesticides related infections & Continuous \\
\hline Gender & Dummy, takes the value of 1 if male and, \\
\hline Live & the \\
\hline Spray & Dummy, $*$ takes the value of 1 if yes and, 0 \\
\hline Read a & otherwise \\
\hline Train & $y$, takes the value of 1 if yes and, 0 otherwise \\
\hline Notic & takes the value of 1 if yes a \\
\hline Use $\mathrm{i}$ & $y$, takes the value of 1 if yes and, 0 otherwise \\
\hline Eat c & takes the value of 1 if yes ar \\
\hline Clea & Dum \\
\hline Dri & akes the value of 1 if yes and, 0 otherwise \\
\hline Affec & Dummy, takes the value of 1 if yes and, 0 otherwise \\
\hline lical attention & Dummy, takes the value of 1 if yes and, 0 otherwise \\
\hline Harvest crops on a treated farmland immediately afte & Dummy, takes the value of 1 if yes and, 0 otherwise \\
\hline & \\
\hline & Dummy, takes the value of 1 if yes and, 0 otherwise \\
\hline
\end{tabular}

Source: Field data, 2019

*Continuous means a discrete variable that can take on an uncountable set of values either numeric or time/date.

*Dummy means a numerical variable that represents categorical data such as gender, race etc.

\section{Key Findings}

\subsection{Exposure to pesticides: A reality for school going population}

Apart from smallholder farmers, pesticides suppliers, and plantation workers who are exposed to pesticides as they handle these chemicals on a daily basis, students are potentially exposed to the noxious effects of these chemicals used in nearby farmlands. Data sourced from students show that $65 \%$ of school children live closer to farmlands that are sprayed with pesticides and also carry out pesticides related farming activities on weekends. Meanwhile only $35 \%$ of students do not live closer to sprayed farmlands. This shows that students are not only exposed to pesticides in schools, they also handle these toxic chemicals during on-farm activities. Following this finding, it is seen that although some students do not live closer to sprayed fields, they are equally exposed to pesticides during school hours as most of the schools are located closer to banana plantations where aerial sprays are carried out on a daily basis. 


\subsubsection{Pesticide use by students: An activity commonly practised by male gender}

Unlike farmers who use pesticide on a daily basis, students are equally involved in the use of these chemicals. Some are exposed to pesticides either during on-farm activities or in schools. Findings revealed clearly that pesticides use among students is mostly done by male students (Figure 2).

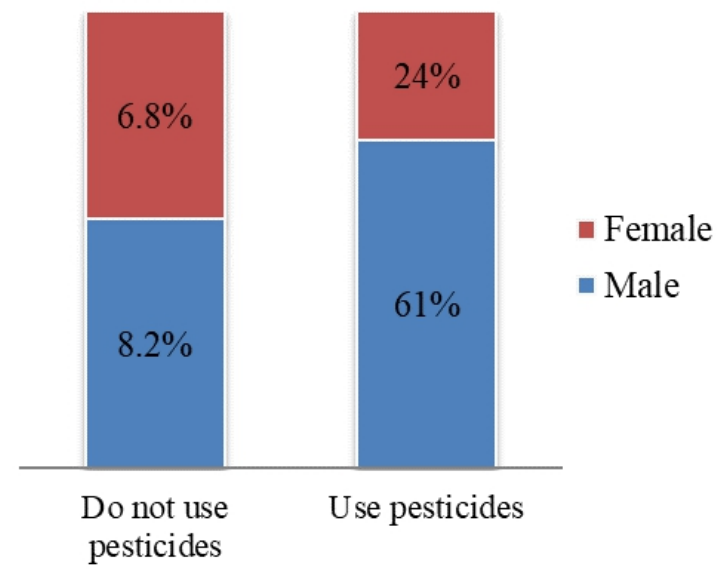

Figure 2: Students who use pesticides

\subsubsection{Reasons why students use pesticides across different schools}

Spraying pesticides is an activity that concerns mainly the farmers. In a community where school going population is more and more involved into this activity, it becomes imperative to know why these school going children are into this delicate activity. Findings revealed that students spray and manipulate pesticides for the following reasons: help their parents to spray; spray on weeds at home; spray in people's farms for remuneration and spray in their own personal farms/gardens (Table 3).

Table 3: Reasons why students use pesticides

\begin{tabular}{lcc}
\hline Reason & Frequency of respondents & $\%$ \\
\hline Help parents to spray & 210 & 41.2 \\
Spray in people's farmlands for remuneration & 190 & 37.3 \\
Spray in personal farmlands & 60 & 11.7 \\
Spray on weed at home & 50 & 9.8 \\
\hline
\end{tabular}

Source: Field data, 2019

In order to rank the reasons for using pesticides by students and to see if these reasons differ across sampled schools, the Kruskal-Wallis test (H-test) was used (Table 4). Based on the Mean Ranks of the H-test, it was noticed that among students who handle and use pesticides, students in Lycée Technique de Loum, GSS Babong and Collège Polyvalent Penja with relatively higher mean ranks, use pesticides for a plethora of reasons (spraying their parents' 
farmlands, their personal farmlands, for remuneration, own agrochemical shops, and transport/supply agrochemicals to local farmers) than their counterparts in GBHS Manengwassa, CAMEL, SAR/SM Badjokip, TISSERINS Njombe, GBHS Penja, CETIC de Njombe, and GBHS Njombe with relatively lower mean ranks (Table 4). In this same vein, the H-test statistic indicated that there was a statistically significant difference in the reasons why students are more involved in the use of pesticides across different schools $\left(X^{2}=95.543, \mathrm{p}<0.05\right)$. This implies that the reasons that prompt students to use pesticides differ from one school to another as students have diverse reasons that motivate them.

Table 4: Ranking reasons for using pesticides by students according to school

\begin{tabular}{ccccc}
\hline School & $\begin{array}{c}\text { Frequency } \\
\text { (n) }\end{array}$ & Mean Rank & $\begin{array}{c}\text { Chi- } \\
\text { Square }\end{array}$ & p-level \\
\hline GBHS Manengwassa & 51 & 217.87 & 95.543 & $0.000^{*}$ \\
CAMEL & 51 & 215.50 & & \\
Lycée Technique de Loum & 46 & 307.22 & & \\
SAR/SM Badjokip & 39 & 223.73 & & \\
TISSERINS Njombe & 52 & 139.06 & & \\
GBHS Penja & 21 & 299.98 & & \\
CETIC de Njombe & 58 & 253.83 & & \\
GSS Babong & 28 & 324.00 & & \\
GBHS Njombe & 123 & 260.80 & & \\
Collège Polyvalent & 41 & 388.84 & & \\
\hline
\end{tabular}

Source: Calculations based on field data, 2019

*Significant at 0.05 probability level

\subsubsection{Pesticide use among students: Frequently used by older than younger students}

A comparative analysis among students revealed that older students spray pesticides more than younger students (Figure 3 ). The mean and median values of younger and older students indicate that older students are more involved in pesticides use than younger students in a whole farming season. This is justified by the fact that the mean and median values of the older group of students are relatively higher than the mean and median values of the younger group.

Given that the interquartile range of the two groups of students is the same, the standard deviation of these groups shows a slight difference indicating that there is an observable difference in pesticides use within students found in each group or younger students vary in their use of pesticides than older students. 
Figure 3: Frequency of pesticide used by young and older students

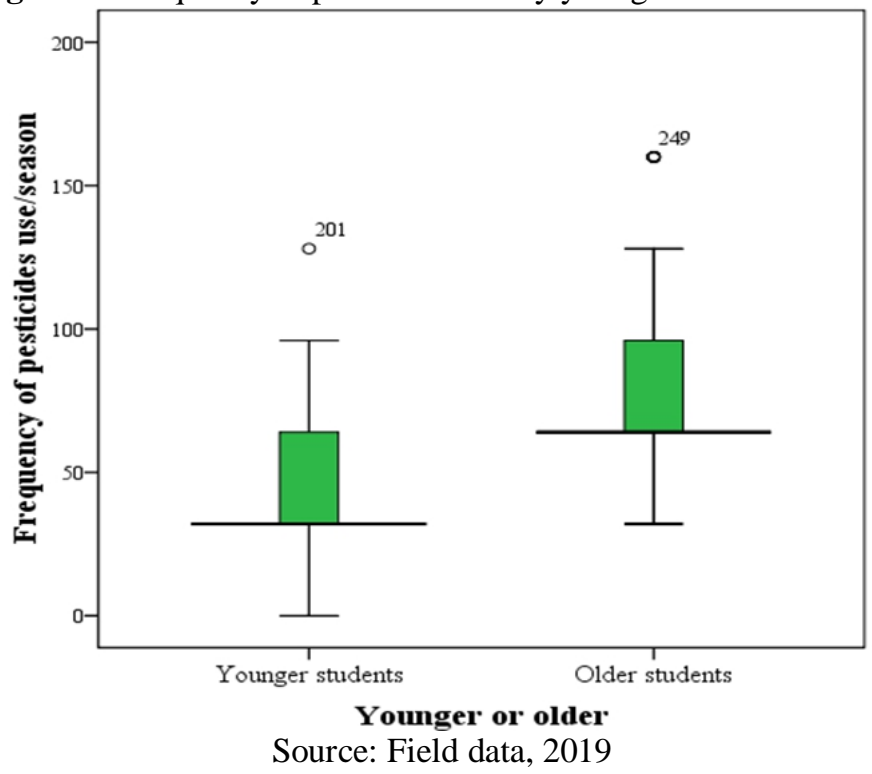

\subsubsection{Pesticide use on average: Mostly used by older than younger students}

Following the result of the U-Test aimed at determining if younger students tend to use less of pesticides on average than their older counterparts (Table 5), it is noticed that the U-Test was statistically very significant $(0.000$, $\mathrm{p}<0.05)$. Since the U-Test was significant, it implies that we reject the null hypothesis $\left(\mathrm{H}_{0}\right)$ and accept the alternative hypothesis $\left(\mathrm{H}_{1}\right)$. Hence, older students spray pesticides more on average than their younger counterparts, although they are all exposed to pesticides harmful effects in farms and in schools, the former are more exposed to pesticides infections than the latter. One can infer from the findings that among students who have sprayed pesticides for more than five years, older students frequently spray than their younger counterpart and equally vulnerable than them.

Table 5: Pesticide use on average by younger and older students

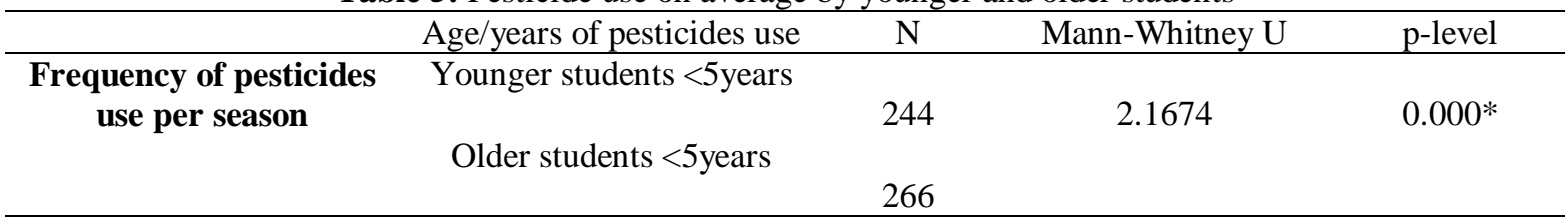

Source: Calculations based on field data, 2019

*Significant at 0.05 probability level 


\section{Factors influencing school going population exposure to agropesticide}

\subsection{Age}

Pesticides are harmful to all population. Some users are affected after spraying these chemicals while others are not. Findings revealed that some students witness pesticides effects while others do not. A number of factors are responsible for school going population exposure to agropesticides and age is one of the factors that determine exposure. While it is known that children are more exposed to these chemicals than adults, this study revealed that older students are more vulnerable than younger students because older students use pesticides on average more than younger students and therefore become more vulnerable.

\subsection{Proximity to agroindustrial plantations}

Some students use, touch and manipulate pesticides while others do not. For those that do not use pesticides, the only exposure pathway is the distance that separates schools and residence from plantations where aerial sprays are done. Findings revealed $65 \%$ of students live in proximity to agroindustrial plantations. Also, some schools are located between 5 and $500 \mathrm{~m}$ away from these plantations and this exposes students to the daily aerial sprays of pesticide carried out in these agroplantations (Table 6).

Table 6: Geographical distance between schools and agroplantations

\begin{tabular}{ccc}
\hline SN & School & Distance (metres) \\
\hline 1 & CETIC de Njombe & 5 \\
2 & Collège Polyvalent & 80 \\
3 & GBHS Njombe & 115 \\
4 & CAMEL & 239 \\
5 & GBHS Penja & 591 \\
6 & GBHS Manengwassa & 725 \\
7 & TISSERINS Njombe & 802 \\
8 & Lycée Technique de Loum & 1327 \\
9 & GSS Babong & 9963 \\
10 & SAR/SM Badjokip & 11973 \\
\hline
\end{tabular}

Source: Field data (January, 2020)

\subsection{Wind direction and speed}

Weather conditions during application (i.e., wind speed and direction, temperature, relative humidity, and air stability at the application site) influence spray drift. Other related factors include: equipment and application techniques (i.e., sprayer type, size and type of nozzles, spray pressure, spray volume rate, air flow rate, driving speed, sprayer's setup, etc.) and operator's care, attitude, and skill. Through the aforementioned factors, wind transports pesticides residues from nearby agroplantations into school yards. Findings revealed that the dominant wind blows from the West-South-West (WSW) 
direction at the speed of $30 \mathrm{~m} / \mathrm{s}$. This wind is responsible for the drift of pesticide to non-target areas like students' residence and schools.

\subsection{Using pesticide without individual protection clothing}

Students use pesticides for various reasons in the study area. As already mentioned, $85 \%$ of students use pesticides with little or no knowledge and they have contact with chemicals on and off the farms. Findings revealed that over $61 \%$ of students do not make use of individual protection clothing and therefore have dermal contacts with pesticides and inhalation as they touch and manipulate these chemicals. Some drink and eat during the application and in the course of that they are highly exposed.

\subsection{Para occupational or take-home pesticide residues}

Take home pesticides is a major pathway for school going population exposure. Smallholder farmers and household members who use pesticides on a daily basis constitute a major pathway for children exposure. Data sourced from smallholder farmers revealed that over $71 \%$ of them do not use any individual protection equipment during application. In this light, pesticide residues accumulate on clothes which are later taken back home. This take home residue is a source of a great chain of contamination of children back at home as they easily get in contact with spraying equipment ${ }^{6}$.

\section{Correlation between students' level of education and some hypothesized explanatory variables}

Students handle and use pesticides without strict respect of the legal framework on the safe use of these toxic chemicals. However, in order to determine if there is a correlation between students' level of education and some hypothesized explanatory variables (drink during pesticides application, eat during pesticide use, read and interpret pesticides pictograms before use, wear individual protection clothing during pesticides use, clean the body immediately after using pesticides, harvest crops on a treated farmland immediately after spraying pesticides, spray pesticides under windy weather conditions, receive training in pesticides use, affected by take home pesticide residues and seek for medical attention when symptoms of pesticide harmful effects manifest on the body), the Chi-Square test was employed (Table 7).

Results revealed that there was a correlation between students' level of education with the practices of not reading and interpreting pesticide pictograms before use, little training (knowledge) in pesticide use, little or no use of individual protection equipment, drinking during pesticide use, and not cleaning the body immediately after using pesticides $(\mathrm{p}<0.05)$ (Table 7$)$. With

\footnotetext{
${ }^{6}$ Interviews with household heads on the origin of some diseases among children
} 
the p-values being statistically significant, this implies that students' lack of knowledge on the use of pesticide exposes them to the noxious effects of these chemicals.

Meanwhile, there was no correlation between students' level of education and the practices of spraying pesticide under dry and windy weather conditions and eating during pesticide application ( $\mathrm{p}>0.05)$. This implies that these variables are not among pesticides exposure pathways.

Table 7: Summary of Chi-Square results

\begin{tabular}{lcccc}
\hline Variable & Description & $\begin{array}{c}\text { Frequency } \\
\text { (n) }\end{array}$ & $\begin{array}{c}\text { Chi- } \\
\text { Square }\end{array}$ & $\begin{array}{c}\text { p- } \\
\text { level }\end{array}$ \\
\hline $\begin{array}{l}\text { Live closer to areas where aerial sprays are } \\
\text { carried out }\end{array}$ & Yes & 404 & 33.094 & $0.000^{*}$ \\
Spray under dry and windy weather & No & 106 & & \\
conditions & Yes & 392 & 1.599 & $0.450^{\mathrm{n}}$ \\
Read and interpret pesticide pictograms & No & 118 & & $\mathrm{~s}$ \\
before use & Yes & 77 & 11.355 & $0.003^{*}$ \\
Training in pesticide use & No & 433 & & \\
& Yes & 46 & 21.832 & $0.000^{*}$ \\
Notice pesticides health effects & No & 464 & & \\
& Yes & 420 & 25.742 & $0.000^{*}$ \\
Use individual protection equipment to & No & 90 & & \\
spray pesticides & Yes & 198 & 23.220 & $0.000^{*}$ \\
Eat during pesticides application & No & 312 & & \\
& Yes & 149 & 1.313 & $0.519^{\mathrm{n}}$ \\
Clean the body immediately after using & No & 361 & & $\mathrm{~s}$ \\
pesticides & Yes & 116 & 16.243 & $0.000^{*}$ \\
Drink during pesticides treatment & No & 394 & & \\
& Yes & 331 & 10.609 & $0.005^{*}$ \\
Affected by take-home pesticides residues & No & 179 & & \\
& Yes & 411 & 23.016 & $0.000^{*}$ \\
Seek for medical attention when symptoms & No & 99 & & \\
of pesticides effects appear on the body & Yes & 275 & 1.6112 & $0.000^{*}$ \\
Harvest crops on the same farmland & No & 235 & & \\
immediately after spraying pesticide & Yes & 300 & 16.975 & $0.000^{*}$ \\
\hline & No & 210 & & \\
\hline
\end{tabular}

Source: Calculations based on field data, 2019

*Significant at $5 \%(\mathrm{p}<0.05)$; ns=not significant

\section{Incidence of pesticide contamination among school going population}

Pesticide related health symptoms manifest on the body when someone is exposed to it. Some symptoms manifest within a shorter period of time, say within 24 hours after exposure while others take a longer time to appear. These effects are short and long term.

A comparative study among students who are more exposed and those who are less exposed in terms of nearness to agroplantations revealed that 
inhabitants as well as school children living closer to these agroplantations tend to bear the greatest brunt.

Symptoms/illnesses common among students were blurred vision (eye contact with pesticides), common cold, and itches of the body, anorexia and redness of the body, bronchitis, leukemia, asthenia, asthma, among others. Table 8 shows a detail result of symptoms and illnesses common among students.

Table 8: Pesticide related illnesses among school going population nearer agroplantations

\begin{tabular}{ccccccc}
\hline School & $\begin{array}{c}\text { GBHS } \\
\text { Manengwassa }\end{array}$ & CAMEL & $\begin{array}{c}\text { GBHS } \\
\text { Njombe } \\
(\%)\end{array}$ & $\begin{array}{c}\text { CETIC de } \\
\text { Njombe } \\
(\%)\end{array}$ & $\begin{array}{c}\text { Collège } \\
\text { Polyvalent } \\
(\%)\end{array}$ & $\begin{array}{c}\text { GBHS } \\
\text { Penja } \\
(\%)\end{array}$ \\
\hline Bymptom/illness & $(\%)$ & 23.7 & 12.1 & 10.5 & 14.7 & 19.2 \\
Common cold & 8.3 & 8.6 & 14.1 & 14.05 & 6.6 & 18.02 \\
Body itches & 18 & 5 & 5.4 & 8.9 & 10.8 & 16.9 \\
Anorexia & 19.3 & 12.9 & 11.3 & 6.5 & 6.3 & 10.5 \\
Body redness & 9.9 & 8.2 & 7 & 17.8 & 11.8 & 5.2 \\
Bronchitis & 4.8 & 4.3 & 10.7 & 6.8 & 15 & 4.7 \\
Leukemia & 9.7 & 4.3 & 3.4 & 14.6 & 5.8 & 4.04 \\
Asthenia & 6.1 & 3.6 & 10.8 & 6.8 & 3.2 & 3.2 \\
Toxicity & 5.8 & 9 & 5.9 & 3 & 10.8 & 4.04 \\
Dry cough & 7.5 & 11.8 & 8.5 & 2.7 & 2.9 & 3.8 \\
Asthma & 5.2 & 4.3 & 7.4 & 4.3 & 3.4 & 4.6 \\
Vomiting & 3 & 4.3 & 3.4 & 4.05 & 8.7 & 5.8 \\
\hline
\end{tabular}

*Students experience a combination of more than one symptom/illness

Aerial application of pesticides may results in drift to neighbouring areas. Distance from sprayed farms to non-point source areas determines the rate of vulnerability of population living in these areas as well as the amount of pesticides carried away in the air.

Meanwhile for schools that are located kilometres away from agroplantations, few cases of pesticide infections were registered (Table 9). Nausea, dry cough, and sneezing, itches, headache and excessive sweat were the only symptoms reported by students. It should be noted here that these schools are located kilometres away from the plantations and students are less exposed. 
Table 9: Pesticide illnesses among school going population further from agroplantations

\begin{tabular}{ccccc} 
School & $\begin{array}{c}\text { Lycée } \\
\text { Technique de } \\
\text { Loum }\end{array}$ & $\begin{array}{c}\text { TISSERINS } \\
(\%)\end{array}$ & $\begin{array}{c}\text { GSS } \\
\text { Babong } \\
(\%)\end{array}$ & $\begin{array}{c}\text { SAR/SM } \\
\text { Badjokip } \\
(\%)\end{array}$ \\
\hline Nausea & 10.1 & 15.06 & 12.9 & 9.3 \\
Dry cough & 10.7 & 12.9 & 9.03 & 12.9 \\
Sneezing & 3.8 & 7.4 & 11.4 & 17.8 \\
Itches & 6.3 & 7.4 & 8.4 & 3.6 \\
Headache & 7 & 1.2 & 4.8 & 5 \\
Excessive sweat & 7 & 3.7 & 1.2 & 3.6 \\
\hline
\end{tabular}

Source: Field data, 2019

*Students experience a combination of more than one symptom

\section{Discussion}

Little or no research had been done in Cameroon in general and the Littoral Region in particular that demonstrated the role of school going population in pesticide use and their exposure to its harmful effects via different exposure pathways. This was one of the first studies to report such bold findings.

Exploring the role of students in pesticides use, this study proved that majority of school going population use pesticides with mostly male students involved in this activity. These are secondary school students who might have little or no knowledge pertaining to the use of pesticide. The finding corroborates that of Nanfa et al., (nd) in Cameroon and Nyakundi et al., (2010) in Kenya who related the involvement of youth in agriculture and use of pesticides to the lack of jobs and search for school fees which expose them to these chemicals. The findings of these authors therefore lent credibility to the present findings.

Pesticides can affect students out of school yards. But potential exposure in schools is also inevitable. The US Environmental Protection Agency (US, EPA) stated that ..."during any normal school day, children and school personnel can be exposed to pesticides especially if the label directions were not followed as chemicals may become airborne and settle on all surfaces".

Exploring students' exposure to pesticides use in agriculture revealed a number of insights that support and extend existing knowledge on proximity as an exposure pathway. Firstly, with regards to nearness to agricultural holdings and exposure of school going population, findings support previous studies (Fenske et al., 2000; Petchuay et al., 2006; Curwin et al., 2007; Panuwet et al., 2009; Morgan, 2012; Rohitrattana, 2014) that suggest that residential proximity to pesticides treated farmlands and transfer of pesticides from the work place back to the house (Para occupational or take home exposure) are exposure pathways through which children are contaminated. 
Secondly, Morgan (2012) identified home-used pesticides and food fibres as other pathways through which children can be affected. In the same vein, other authors (Fenske et al., 2013; Hurley et al., 2014) also stressed on nearness to farm holdings and exposure to pesticides spray drift as the most common pathways. The findings of this current study authenticate the findings of Fenske et al., (2000); Nuckols et al., (2004); Franklin \& Worgan (2005); Curwin et al., (2006); Morgan (2012); Fenske et al., (2013); and Hurley et al., (2014). This study posits that school going population is exposed to pesticides via numerous pathways hence, making a new contribution to the existing literature by exposing a need to consider school going population vulnerability in future studies exploring pesticides harmful effects among population.

Spray drift continues to be a major problem in agropesticides. Numerous studies (Hanna \& Schaefer, 2014; Graeme, 2017; Baio et al., 2019; Desmarteau et al., 2019) have confirmed that air is one of the main pathways through which pesticides reach undesirable targets. This current study has shown that air drift triggered by wind from nearby banana plantations where aerial sprays are done, carry particles of pesticides to undesirable targets like schools and residence. The dominant wind recorded was from the West-SouthWest (WSW) direction and blows towards the east at the speed of $30 \mathrm{~m} / \mathrm{s}$. This wind is responsible for the drift of pesticides particles from the banana estates to nearby dwellings and schools. For example, Feumba (2015) shows that, the prevailing wind in the Littoral Region of Cameroon including the Mungo Corridor are from the South West. This finding therefore lent credibility to the current study. Distance from treated farmland and school is also a major factor of vulnerability. The current study revealed that most school compounds are between 5 to $500 \mathrm{~m}$ from pesticides treated farmlands. This increases the risk of exposure of school children.

Interpreting pesticides pictograms seems a difficult task for pesticides users. Some users neglect pictograms while others do not understand them at all. Although the current study was conducted among school going population who could interpret pesticides pictograms better than uneducated peasant farmers, findings have shown that students are not different. However, findings revealed students' inability to interpret pictograms. In this line, students' knowledge on the intended messages on pesticide pictograms shows their degree of exposure. Those who interpreted pictograms wrongly were likely to misuse pesticides and therefore liable to be affected than those who interpreted them correctly. These findings authenticate the research findings of Tourneux (1993) conducted in Northern Cameroon that pesticide users lack understanding of phytosanitary pictograms which favoured the abusive use of pesticides. In a similar survey (Ajayi et al., 2007) in Ivory Coast, it was revealed that users are ignorant of pesticides pictograms and avoided medical care on the assumption that signs and symptoms of pesticides poisoning are a 
normal phenomenon and need no medical attention. This attitude further broadens the risk of long term effects of pesticides poisoning. The current research revealed similar results like the findings of Tourneux (1993) and Ajayi et al., (2007). However, the present study demonstrated this knowledge gap among school going population thus, giving a new insight on the existing literature and paving the way for future research exploring student population exposure to pesticides.

A study conducted by Antle \& Pingali (1994) states that scientific confirmed pesticide related symptoms and acute illnesses are headaches, stomach pains, vomiting, skin rashes, respiratory problems, eye irritations, sneezing, seizures, and coma among others. Similarly, the US EPA Office of Research and Development's Asthma Research Strategy reports that "pesticides are listed as one of four environmental pollutants that may influence the induction and exacerbation of asthma and if applied irresponsibly, some pesticides have been linked to long term health problems, including: cancer; leukemia; birth defects; endocrine disruption; asthma; neurological disorders; immune system deficiencies". Exploring archives of health establishments in the study area, findings revealed a number of insights that support the aforementioned findings.

This study reported some pesticides health symptoms on school going population. It was proven that symptoms like cough, itches, vomiting, nausea, and illnesses like eye problems, bronchitis, leukemia, cancer, respiratory problem, anorexia, and diarrhea among others were noticed on school going students who handle pesticides and those who live closer to fields where aerial sprays of pesticides are done. Meanwhile these symptoms were quasi-absent on students who live far away from these farmlands. These symptoms are signs of acute and chronic effects of pesticides that are common among populations. This hypothesis has been widely supported mainly on farmers' health (Horrigan et al., 2002; Matthews et al., 2003; Kamel \& Hoppin, 2004; Kishi 2005; Dick, et al., 2007; Nasterlack 2007; Kamel et al., 2007; Hancock et al., 2008; Ramade, 2008; Tetang \& Foka, 2008; Manfo et al., 2010; Kenko et al., 2017) whereas the present study reported these symptoms on a neutral population which is school going population. It therefore makes a new contribution to the literature by exposing a need to consider school going population in future studies exploring epidemiological studies among population with regards to pesticides.

\section{Conclusion}

This study has proven that school going population is exposed to agropesticides, at home, in schools and during on-farms activities. Over $65 \%$ of students live in proximity to agroindustrial plantations where aerial sprays are done and students are exposed to spray drifts. Findings also revealed that 
students are more and more involved in the use of pesticides as they help their parents to spray on crops $(41.2 \%)$, some spray on weed at home $(9.8 \%)$, others spray as remunerated activities $(37.3 \%)$ while some spray in their personal farmlands (11.7\%). This is where a great chain of pesticides contamination takes root. Results also showed that there was a significant difference between students' level of education and some hypothesized explanatory variables $(\mathrm{p}<0.05)$ which further increases students' risk of contamination. A thorough review of literature showed a dearth of information pertaining to school going population exposure pathways to agropesticides. Therefore, based on the findings of this research, it is recommended that students who are involved in pesticides use must receive training in order to reduce the risk of contamination and also, an environmental impact assessment needs to be carried out in the agroindustrial plantations so as to provide wind barriers in order to reduce spray drifts from entering into school yards and residential areas.

\section{References :}

1. Ajayi, O.C. \& Akinnifesi, F.K. (2007). "Farmers' Understanding of Pesticide Safety Labels and Field Spraying Practices: A Case Study of Cotton Farmers in Northern Côte d'Ivoire." Scientific Research and Essay, 2, 204-210.

2. Ako, A.A, Shimada, J., Kimpei I., Katsuaki K., Takahiro H., Takem G.E.E. \& Iskandar I. (2010). Hydrochemical and isotopic characteristics of water resources in the Banana Plain (Mungo Division) Cameroon. In Zuber A., Kania, J. and Kmiecik E. eds (2010): XXXVIII IAH Congress on Groundwater Quality Sustainability, Krakow, 12-17 Sept 2010, Extended Abstract: 168, University of Silesia Press 2010, Krakow, Poland.

3. Antle J.M \& Pingali P.L. (1994). "Pesticides, Productivity, and Farmer Health: A Philippine Case Study". Amer. J. Agric. Econ., 76: 418-430.

4. Baio F.H.R., Antuniassi U.R., Castilho B.R., Teodoro P.E., \& Silva E.E.d. (2019). "Factors affecting aerial spray drift in the Brazilian Cerrado". PLoS ONE, 14(2): 212-289.

5. Chester G, \& Ward RJ, (1984). "Occupational exposure and drift hazard during aerial application of paraquat to cotton". Environ Contamin Toxicol, 13:551-563.

6. Curwin B.D., Misty J.H., Wayne T.S., Striley C., Reynolds S.J., Alavanja D.H., \& Kromhout H. (2007). "Urinary pesticide concentrations among children, mothers and fathers living in farm and non-farm households in Iowa". Ann Occup Hyg, 51(1):53-65. 
7. Dick F.D, De Palma G., Ahmadi A., Scott N.W, Prescott G.J, \& Bennett J. (2007). 'Environmental risk factors for Parkinson's disease and parkinsonism: The Geoparkinson study". Occup. Environ. Med. , 64: 666-672.

8. Desmarteau D. A, Ritter A.M, Hendley P, \& Guevara M. W. (2019). Impact of Wind Speed and Direction and Key Meteorological Parameters on Potential Pesticide Drift Mass Loadings from Sequential Aerial Applications . Integr Environ Assess Manag, 1-14.

9. Ekeh P. U. \& Njoku C., (2014). "Academic Optimism, Students' Academic Motivation and Emotional Competence in an Inclusive School Setting" European Scientific Journal, 10:127-141.

10. Fenske R.K, Lu C., Nancy J.S., Loewenherz C., Touchstone J., Moate F.T., Allen E.H., \& Kissel J.C. (2000). "Strategies for assessing children's organophosphorus pesticides exposures in agricultural communities". Journal of Exposure Analysis and Environmental Epidemiology, 10, 662-671.

11. Fenske R.A., Lu C., Negrete M., \& Galvin K. (2013). "Breaking the Take Home Pesticide Exposure Pathway for Agricultural Families: Workplace Predictors of Residential Contamination". Am J Ind Med; 56(9): 1063-1071.

12. Feumba R. (2015). Hydrologies et évaluation de la vulnérabilité des nappes dans le bassin versant de Besseke (Douala, Cameroun). Thèse de doctorat/Ph.D. en science de la terre. Université de Yaoundé 1. 254 p.

13. Franklin, C.A., \& Worgan, J. P. (eds.), (2005). Occupational and residential exposure assessment for pesticides. . Chichester, UK: John Wiley \& Sons, Ltd.

14.Frost KR, \& Ware GW, (1970). "Pesticide drift from aerial and ground applications." Agric Eng, 51:460-467.

15. Graeme T. (2017). Weather Essentials for Pesticide Application. GRDC Project Code: TEP00001 - General meteorology for pesticide application booklet. KINGSTON ACT 2604

16. GTZ (2006). Projet pour l'Amélioration de l'accès à l'eau potable et de l'assainissement de base dans les trios communes rurales de Manjo, Loum et Penja/Njombe, Province de Littoral-Cameroun. Douala-Cameroun: German Technical Cooperation.

17. Hancock D.D, Martin E.R, Mayhew GM, Stajich JM, Jewett R, \& Stacy M.A,. (2008). "Pesticide exposure and risk of Parkinson's disease: a family-based case-control study". BMC. Neurol. , 8: 6.

18. Hanna M, \& K. Schaefer. (2014). Factors affecting pesticide drift. Iowa State University 
19. Horrigan L, Lawrence RS, \& Walker P,. (2002). "How sustainable agriculture can address the environmental and human health harms of industrial agriculture". Environ. Health Perspect, 110: 445-456.

20. Hurley J. A., T. A. Green, D. H. Gouge, Z. T. Bruns, T. Stock, L. Braband, K. Murray, C. Westinghouse, S. T. Ratcliffe, D. Pehlman, \& L. Crane (2014). "Regulating Pesticide Use in United States Schools". American Entomologist. Volume 60, Number 2. Pp. 106114

21. Kamel F. \& Hoppin J.A. (2004). Association of pesticide exposure with neurologic dysfunction and disease . Environ. Health Perspect., 112: 950-958.

22. Kamel F, Tanner C, Umbach D, Hoppin J, Alavanja M, \& Blair A. (2007). 'Pesticide exposure and self-reported Parkinson's disease in the agricultural health study". Am. J. Epidemiol, 165: 364-374.

23. Kenko N. D, Asanga B. F., Ngameni T, N, \& Mbida M. (2017). "Environmental and Human Health Assessment in Relation to Pesticide Use by Local Farmers and the Cameroon Development Corporation (CDC), Fako Division, South-West Cameroon". European Scientific Journal, Vol.13, No.21 pp: 1857 - 1881.

24. Kishi M. (2005). The health impacts of pesticides: What do we now know? In The Pesticide Detox: Towards a More Sustainable Agriculture Earthscan, by Pretty. London.

25. Manfo, F.P.T., Moundipa, P.F., Déchaud, H., Tchana, A.N., Nantia, E.A., Zabot, M.T. \& Pugeat, M. (2010). "Effect of agropesticides use on male reproductive function: a study on farmers in Djutitsa (Cameroon)". Env. Toxicol, DOI 10.1002:1-10.

26. Matthews, G., Wiles, T., \& Baleguel, P. (2003). “A survey of pesticide application in Cameroon”. Crop Protection, 22(5), 707-714.

27. Nanfa, D., Atogho T.B., Ndonwi, E.N. \& Fopa, L.G.B. (nd). Environmental and health risk associated with the dissemination of persistent organic pollutants (pops) in Yaoundé. Topic A10: Public health and exposure studies, $7 \mathrm{p}$.

28. Nasterlack M. (2007). "Pesticides and childhood cancer: an update". Int. J. Hyg. Environ Health, 210: 645-657.

29. Nicholas, S. W., B. Jean-Louis, B. Ortiz, M. Northridge, K. Shoemaker, R. Vaughan, \& V. Hutchinson. (2005). "Addressing the childhood asthma crisis in Harlem: The Harlem Children's Zone Asthma Initiative". American Journal of Public Health 95(2): 245249.

30. Nkemleke E.E. (2020). “Assessing Small-Scale Farmers' Attitudes, Practices and Vulnerability to Pesticides Use in Market Gardening 
Crops in M'muockngie (South Western Cameroon)". J Adv Educ Philos, 4(6): 295-305.

31. Nyakundi, W.O., Magoma, G., Ochara, \& Nyende, A.B. (2010). "A survey of pesticide use and application patterns among farmers: a case study from selected horticultural farms in rift valley and central provinces, Kenya". Institute of Biotechnology and Research, Nairobi, Kenya. pp 618-630.

32. Nuckols, J. R., Ward, M. H., \& Jarup, L. (2004). "Using geographic information systems for exposure assessment in environmental epidemiology studies". Environmental Health Perspectives, 112(9), 1007-1015.

33. Okorji P., Igbokwe C., \& Ezeugbor O., (2016). "Relationship between School Climate and Principals' Job Performance in Secondary Schools" European Scientific Journal, 12:55-67.

34. Panuwet P., Prapamontol T., Chantara S., \& Barr D.B. (2009). "Urinary pesticide metabolites in school students from northern Thailand". Int J Hyg Environ Health, 212(3):288-297.

35. Petchuay C., Visuthismajarn P., Vitayavirasak B., Hore P., \& Robson M.G. (2006). "Biological monitoring of organophosphate pesticides in preschool children in an agricultural community in Thailand". Int $J$ Occup Environ Health, 12(2):134-141.

36. Ramade, F. (2008). "Ecotoxicologie." Société Nationale de Protection de la Nature (4p), 4p.

37. Rohitrattana (2014). "Pyrethroid insecticide exposure in school-aged children living in rice and aqua cultural farming regions of Thailand". Risk Management and Healthcare Policy, 7 211-217.

38. Tetang T.J. \& Foka G. (2008). « Utilisation des pesticides dans la zone agricole du Moungo- Evaluation de l'impact sur l'environnement, la santé des populations, et solutions envisageables : cas de la localité de Njombé dans l'arrondissement de Njombé-Penja ». Pesticide Bull, 2:12-16.

39. Tourneux H. (1993). "Smallholder understanding of phytosanitary pictograms in North Cameroon". Cotton and tropical fibres, 48(1): 41-56. 